\title{
关于深源单斜辉石中结构 $\mathrm{OH}$ 的结合机理 *
}

\author{
章礼明 \\ (中国科学院地球化学研究所, 贯阳 550002)
}

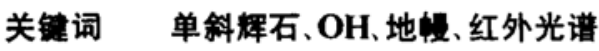

在前人最新研究资料的基础上 ${ }^{[1-9]}$, 本文将对单斜辉石中结构 $\mathrm{OH}$ 替代的复杂机理和晶 体化学进行深人讨论. 非闪石 $\mathrm{OH}$ 可以出现在辉石结构中氧的位置, 并伴随有阳离子替代或 空位来使电荷平衡. 有人认为具有四面体 $\mathrm{Fe}^{3+}$ 的辉石能够吸收 $\mathrm{H}^{+18]}$. Skogoby 等 ${ }^{[7}$ 研究了 51 个 产自不同地质环境的辉石后发现, (1) 几乎所有的样品中均出现痕量的 $\mathrm{OH}$; (2) OH 浓度和地 质产状有关, 并在幔源样品中达最大值. 一般趋势为高压下 $\mathrm{OH}$ 浓度高; (3) 辉石中的 $\mathrm{OH}$ 反映 其相应地质环境中挥发份浓度的某些方面, 却不受表生作用如大气混染的影响; (4) OH 浓度还 与辉石的成分尤其是三价阳离子有一定关系. 他们还分析了 $\mathrm{OH}$ 的取向. 吸收带可分为两组:

(1) $3620-3640 \mathrm{~cm}^{-1}$, 与三价离子有关, 相应的多向性为 $\alpha=\beta, \gamma=0$; (2) 3525,3460 和 3350 $\mathrm{cm}^{-1}$, 与二价离子有关, 多向性为 $\gamma>\alpha=\beta$. (1) 带的 $\mathrm{OH}$ 偶极子出现在辉石结构中 $\mathrm{O} 2$ 位置并指 向 O3, 或者说它和 (001) 斜交, 相对于 $a$ 轴更近于 $b$ 轴. (2)带的 $\mathrm{OH}$ 偶极在(100)面上并近于 $c$ 轴, 可能也出现在 $\mathrm{O} 2$ 位置 ${ }^{[7]}$. Smyth 等 ${ }^{[9]}$ 研究了 $\mathrm{OH}$ 红外吸收率与辉石中阳离子空位的关系.

\section{1 相 关性 分 析}

作者所用 (原始) 数据见 Smyth 等的表 1 和表 2. 其中, 表 1 为电子探针分析结果以及相 应的阳离子数 $(O=6$, 余同); 表 2 为单斜辉石样品在一定方向 ( $\gamma$ 偏振谱和 $\alpha$ 偏振谱)和一定吸 收带 $\left(3470\right.$ 和 $\left.3620 \mathrm{~cm}^{-1}\right)$ 的吸收率以及各样品的 $\mathrm{OH}$ 浓度 ${ }^{[9]}$. 具体的分析操作是根据一定的思 路设计不同的吸收率和阳离子数 (或组合) 对, 求两者之间 (变量) 相关系数 (表 1). 为了文字 上的方便, 下文中作者将所讨论的 3 个吸收带简述为 $3470(\gamma), 3470(\alpha)$ 和 $3620(\alpha), 3470(\gamma)$ 和 3470 $(\alpha)$ 统称 3470 .

\section{2 讨 论}

仔细研究表 1 中的成对变量之间的相关性以及不同变量对相关性的异同或关系, 可以得 出许多重要认识. 现分述如下.

就 3470 而言: (1) $\gamma$ 偏振谱和 $\alpha$ 偏振谱有很好的正相关性. 看来它们所反映的 $\mathrm{OH}$ 结合 机理相同, 但两者的取向是不同的; (2) $\mathrm{Ca}$ 和 $\mathrm{Mg}$ 离子数与吸收率负相关, 所以 $\mathrm{Ca}$ 和 $\mathrm{Mg}$ 或 者说由它们组成的透辉石端员对 $\mathrm{OH}$ 的结合不利; (3) $\mathrm{Al}^{\mathrm{VI}}$ 及 $\mathrm{Na}+\mathrm{K}$ 离子数与吸收率正相 关, 所以 $\mathrm{Al}^{\mathrm{VI}^{1}}$ 及 $\mathrm{Na}+\mathrm{K}$ 或者说硬玉端员有利于 $\mathrm{OH}$ 的被吸收; (4) 因为辉石结构中 $\mathrm{Al}$ 与结 晶压力正相关 ${ }^{[10]}$, 所以通过表中 $\mathrm{Al}$ 的量与红外吸收率的关系可证实高压下单斜辉石的晶体化

1993-12-10 收稿, 1994-05-05 收修改稿.

*国家自然科学基金资助项目. 
表 1 单斜辉石中结构 $\mathrm{OH}$ 红外吸收的部分相关系数

\begin{tabular}{lcccccccc}
\hline & 空 位 & \multicolumn{1}{c}{$\mathrm{Si}$} & \multicolumn{1}{c}{$\mathrm{Al}$} & \multicolumn{1}{c}{$\mathrm{Al}^{\mathrm{VI}}$} & $\mathrm{Al}^{\mathrm{IV}}$ & $\mathrm{Na}+\mathrm{K}^{\mathrm{a}}$ & $\mathrm{Ca}+\mathrm{Na}+\mathrm{K}$ & $\mathrm{Ca}$ \\
\hline $3620(\alpha)$ & -0.582 & -0.168 & -0.288 & -0.323 & 0.264 & -0.289 & 0.558 & 0.365 \\
$3470(\alpha)$ & 0.866 & -0.425 & 0.620 & 0.633 & 0.271 & 0.590 & -0.586 & -0.670 \\
$3470(\gamma)$ & 0.944 & -0.395 & 0.748 & 0.693 & 0.316 & 0.700 & -0.550 & -0.774 \\
\hline & $\mathrm{Fe}$ & $\mathrm{Mg}$ & $\mathrm{Fe}+\mathrm{Mg}$ & $\mathrm{Ca}+\mathrm{Fe}+\mathrm{Mg}$ & & $3620(\alpha)$ & $3470(\alpha)$ & \\
\hline $3620(\alpha)$ & -0.025 & 0.328 & 0.308 & 0.333 & & 1 & & 1 \\
$3470(\alpha)$ & -0.551 & -0.620 & -0.649 & -0.659 & & -0.482 & & \\
$3470(\gamma)$ & -0.413 & -0.755 & -0.761 & -0.768 & & -0.479 & 0.918 & \\
\hline
\end{tabular}

a) 实际上 $\mathrm{K}$ 含量很低.

学利于 $\mathrm{OH}$ 的结合; (5) 根据表 1 中阳离子空位、 $\mathrm{Ca}$ 和 $\mathrm{Al}$ 离子数与 3470 吸收率的关系可得 出, 具有阳离子空位、 $\mathrm{Ca}$ 较少而 $\mathrm{Al}$ 较多的 Eskola 端员 $\left(\mathrm{Ca}_{0.5} \mathrm{AlSi}_{2} \mathrm{O}_{6}\right)$ 显然利于 $\mathrm{OH}$ 吸收. Smyth 等曾认识到 $3470(\gamma)$ 与空位的相关性 ${ }^{[97}$ (亦见本文表 1); (6) 如果承认 $\mathrm{OH}$ 与 M2 位置有 关 ${ }^{[9]}$, 依据表 1 则可以进一步分析 M2 位置不同元素阳离子对 $\mathrm{OH}$ 结合的不同影响. 因为 $\mathrm{Na}+\mathrm{K}$ 与吸收率正相关而 $\mathrm{Ca}, \mathrm{Fe}$ 和 $\mathrm{Mg}$ 都与吸收率负相关, 有可能 $\mathrm{H}^{+}$和 $\mathrm{M}^{+}$(注: $\mathrm{M}$ 示意阳 离子, 余同 ) 以一定比例进人未由 $\mathrm{M}^{2+}$ 占据的 $\mathrm{M} 2$ 晶位. 在这种情况下, $\mathrm{M}^{3+}$ 进人 $\mathrm{M} 1$ 将起到 维护局部电荷平衡的作用, 这可从 $\mathrm{Al}^{\mathrm{VI}}$ 与吸收率的正相关得到一定体现. 空位的作用应该与 $\mathrm{M}^{3+}$ 相似; (7) $\mathrm{Si}, \mathrm{Al}^{\mathrm{IV}}$ 和 $\mathrm{Fe}$ 与 $\mathrm{OH}$ 均无明显相关性. 因为 $\mathrm{Fe}$ 的价态不详, $\mathrm{Fe}^{3+}$ 或雉辉石端 员与 $\mathrm{OH}$ 的关系也不明确. 作者推测它们可能分别和 $\mathrm{Al}^{\mathrm{V}}$ 或硬玉端员的作用相同.

$3620(\alpha)$ 与 $3470(\gamma)$ 和 $3470(\alpha)$ 所反映的 $\mathrm{OH}$ 结合机理不同. $3620(\alpha)$ 和阳离子的相关性都 较弱, 具体规律不明朗. 值得注意的是 $3620(\alpha)$ 和 3470 成弱的反相关性. 进一步分析似乎可 得: 辉石的深部结晶环境中 $\mathrm{H}$ 总存在被辉石晶体结合的趋势, 而且主要是由 3470 显示的或 者说尽可能以与 3470 相应的结合机理实现 ${ }^{[9]}$. 如果实际情形不利于 3470 所反映的 $\mathrm{OH}$ 结 合, 便可能发生具有较大随机性的 $3620(\alpha)$ 的 $\mathrm{OH}$ 结合.

总之, 作者认为, 深源单斜辉石和其它无水矿物中结构 $\mathrm{OH}$ 值得地学界的重视; 对于痕量 $\mathrm{OH}$ 的红外吸收特征的严格阐明将有赖于本文所进行的对局部精细结构的研究.

致谢 本文系作者在傅平秋研究员和张哲儒研究员指导下所作博士论文的一部分. 刘高 魁高级工程师协助完成有关红外实验. 完稿后承蒙欧阳自远研究员审阅. 深致谢忱.

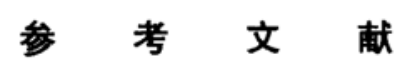

[1] Bell, D. R., Rossman, G. R., Science, 1992, 256: 1391-1397.

[2] Thompson, A. B., Nature, 1992, 368: 295-302.

[3] Bell, D. R., Nature, 1992, 357:646-647.

[4] Bell, D. R., Rossman, G. R., Contrib. Mineral. Petrol., 1992, 111: 161- 178.

[5] Bai, Q., Kohlstedt, D. L., Phys. Chem. Mineral., 1993, 19:460-471.

[ 6] Ingrin, J. et al., Eur. J. Mineral, 1989, 1:327-341.

[7] Skogby, H. et al., Am. Mineral., 1990, 75: 764-774.

[ 8] Skogby, H., Rossman, G. R., Am. Mineral., 1989, 74: 1059-1069.

[ 9] Smyth, J. R. et al., Nature, 1991, 351: 732-735.

[10] Thompson, R. N., Mineral Mag., 1974, 39: 768-787. 